\title{
Collagen synthesis by cell lines derived from Mov-13 mouse embryos which have a lethal mutation in the collagen a1(I) gene
}

\author{
Marie DZIADEK, ${ }^{*} \ddagger$ Rupert TIMPL* and Rudolf JAENISCH $\dagger$ \\ *Max-Planck-Institute für Biochemie, 8033 Martinsried bei München, Germany, and †Whitehead Institute for Biomedical \\ Research, Massachusetts Institute of Technology, 9 Cambridge Center, Cambridge, MA 02142, U.S.A.
}

\begin{abstract}
Mouse embryos homozygous for the Mov-13 mutation produce no collagen I, owing to transcriptional blockage of the collagen $\alpha 1$ (I) gene by a retroviral insert. Fibroblast-like cell lines derived from these embryos were compared with similar lines derived from heterozygous and wild-type embryos with respect to the total amounts, and types, of collagen synthesized. Total collagen synthesized by either cloned or uncloned cell lines correlated with their genotype, demonstrating no compensation for absence of collagen I production by an increase in synthesis of other collagen types. Procollagen $\alpha 2$ (I) chains were not detected in the homozygous cell lines, demonstrating that these chains do not form homotrimers, nor do they form heterotrimers with $\alpha$-chains of other collagen types. Procollagen III levels were quantified by radioimmunoassay and found to be similar in all cell lines.
\end{abstract}

\section{INTRODUCTION}

The Mov-13 mouse mutation, which causes midgestation lethality in homozygous embryos, was created by infection of embryos with Moloney murine leukaemia virus (Jaenisch et al., 1983). A single copy of the proviral DNA inserted into the first intron of the collagen $\alpha 1$ (I) gene, which codes for the most ubiquitous structural protein of connective tissue. Viral insertion resulted in complete transcriptional inactivation of this gene (Schnieke et al., 1983) by a changed conformation of chromatin at the $5^{\prime}$ end of the gene (Breindl et al., 1984), which inhibits the initiation of transcription (Hartung et al., 1986). Embryos homozygous for the proviral insert produce no collagen I (Löhler et al., 1984; Kratochwil et $a l ., 1986)$ and die between days 13 and 14 of gestation, apparently as a result of rupture of major blood vessels (Löhler et al., 1984). However, many organs and tissues which were explanted from homozygous embryos before death differentiated in a similar manner to control embryonic organs and contained abundant collagen fibrils in the interstitial matrix (Kratochwil et al., 1986). It appears that other collagen types can substitute for the structural and/or morphogenetic role of collagen I in these tissues. The other interstitial collagens, types III and $\mathrm{V}$, were the major collagens synthesized by homozygous tissues, but it was not possible to determine whether these collagens were produced in elevated amounts to compensate for the absence of collagen I (Kratochwil et al., 1986). Collagen I normally exists as a heterotrimer of $\alpha 1$ (I) and $\alpha 2(\mathrm{I})$ chains in a 2:1 ratio (Bornstein \& Sage, 1980). Although the $\alpha 2(\mathrm{I})$ gene is not affected by the mutation of the $\alpha 1$ (I) gene, and $\alpha 2(\mathrm{I})$ mRNA is produced (Schnieke et al., 1983), $\alpha 2(\mathrm{I})$ chain trimers were not detected in homozygous embryos by immunostaining (Löhler et al., 1984) or as synthetic products in organ cultures (Kratochwil et al., 1986). Unlike $\alpha 1$ (I) chain trimers (Uitto, 1979; Prockop \& Kivirikko, 1984), $\alpha 2(\mathrm{I})$ chain trimers are unstable molecules at body temperature (Tkocz \& Kühn, 1969) and are likely to be rapidly degraded.

In the present study we have analysed collagen synthesized by cloned and uncloned fibroblast-like cell lines (which were established from mutant embryos) to determine whether the mutant phenotype is maintained in culture and whether the overall pattern and quantity of collagen types is altered in the mutant cell lines to compensate for decreased amounts, or the absence, of collagen I.

\section{MATERIALS AND METHODS}

\section{Cell culture and labelling}

The cell lines from wild-type (M13-2), heterozygous (M13-4) and homozygous (M13/5) embryos which had been transformed with simian virus 40 were described previously (Schnieke et al., 1983). Cloned cell lines (15cl $4 ; 2 \mathrm{cl} 1 ; 4 \mathrm{cl} 4$ ) were derived from these original wild-type, heterozygous and homozygous cell lines respectively. Cell lines were maintained in DMEM (Flow Laboratories, Bethesda, MD, U.S.A.) containing $10 \%$ (v/v) foetal-calf serum. For analysis of collagen synthesis, subconfluent cultures were preincubated in serum-free DMEM containing (per $\mathrm{ml}$ ) $50 \mu \mathrm{g}$ of sodium ascorbate, $100 \mu \mathrm{g}$ of $\beta$-aminopropionitrile fumarate and 400 units of penicillin for $12 \mathrm{~h}$, followed by incubation in fresh medium containing, in addition, $\mathrm{L}-\left[5-{ }^{3} \mathrm{H}\right]$ proline $(50 \mu \mathrm{Ci} / \mathrm{ml} ; 13.4 \mathrm{Ci} / \mathrm{mmol}$; New England Nuclear) (Aumailley et al., 1982). At the time of labelling, cell counts were $(6-7) \times 10^{6} / 60 \mathrm{~cm}^{2}$ Petri dish. Cells were incubated for $24 \mathrm{~h}$, after which the medium and cell layers were separated for analysis. Cell debris was removed from the medium by low-speed centrifugation, proteinase inhibitors were added (2 mM-PMSF, $2 \mathrm{mM}-\mathrm{NEM}$ and $10 \mathrm{~mm}$-EDTA), and samples were cooled to $4{ }^{\circ} \mathrm{C}$. Cells were suspended in $0.5 \mathrm{M}$ $\mathrm{NaCl} / 50 \mathrm{~mm}-\mathrm{Tris} / \mathrm{HCl}$ buffer, $\mathrm{pH} 7.4$, containing 
$4 \mathrm{mM}$-PMSF, $4 \mathrm{~mm}$-NEM and $10 \mathrm{~mm}$-EDTA as proteinase inhibitors, and freeze-thawed twice.

\section{Total collagen synthesis}

Collagen synthesis was quantified by determination of incorporated $\left[{ }^{3} \mathrm{H}\right]$ proline modified to $\left[{ }^{3} \mathrm{H}\right]-$ hydroxyproline. Samples from the medium and cell-layer fractions $(1.0 \mathrm{ml})$ from three separate culture dishes of each cell line were dialysed exhaustively against $0.08 \mathrm{M}$-acetic acid, freeze-dried, and hydrolysed in duplicate at $110^{\circ} \mathrm{C}$ for $24 \mathrm{~h}$ with $6 \mathrm{M}-\mathrm{HCl}$ containing $0.05 \%$ 2-mercaptoethanol under $\mathrm{N}_{2}$. $\left.{ }^{3} \mathrm{H}\right]$ Proline and $\left[{ }^{3} \mathrm{H}\right]$ hydroxyproline radioactivities were determined by amino acid analysis as described previously (Krieg et al., 1978).

\section{Determination of collagen types}

Triple-helical collagen synthesized in cell culture was assayed by gel electrophoresis after pepsin digestion. Rat collagen I $(50 \mu \mathrm{g} / \mathrm{ml})$ was added as carrier to labelled medium samples, and these and cell-layer fractions were precipitated with $30 \%$ saturated $\left(\mathrm{NH}_{4}\right)_{2} \mathrm{SO}_{4}$ at $4{ }^{\circ} \mathrm{C}$ overnight. After centrifugation, pellets were resuspended

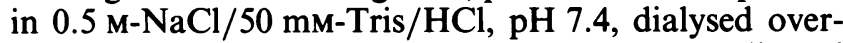
night $0.08 \mathrm{M}$-acetic acid/0.02 $\mathrm{M}$-sodium acetate adjusted to $\mathrm{pH} 2.0$ with $\mathrm{HCl}$, incubated with pepsin $(0.1 \mathrm{mg} / \mathrm{ml})$ for $6 \mathrm{~h}$ at $18{ }^{\circ} \mathrm{C}$, and the reaction was stopped by neutralization. Aliquots from each line were analysed by $\mathrm{SDS} / 5 \%-(\mathrm{w} / \mathrm{v})$-polyacrylamide-gel electrophoresis using the buffer system of Laemmli (1970), and radioactive bands were detected by fluorography (Bonner \& Laskey, 1974). Some protein samples were reduced by treatment with $5 \%(\mathrm{v} / \mathrm{v}) 2$-mercaptoethanol before electrophoresis. Standards used for identification of collagen types were pepsin-treated rat collagen I, human collagens IV and V, and bovine collagen III obtained from skin or placenta (Miller \& Rhodes, 1982).

\section{Immunological assays}

Immunoprecipitation of collagen I was done with labelled medium and cell-layer samples which were not precipitated with $\left(\mathrm{NH}_{4}\right)_{2} \mathrm{SO}_{4}$ but were dialysed against phosphate-buffered saline $(0.12 \mathrm{M}-\mathrm{NaCl} / 12 \mathrm{~mm}$-sodium phosphate/4 mm-potassium phosphate buffer, $\mathrm{pH} 7.2$ ) containing $0.04 \%$ Tween 20 . Samples were incubated for $24 \mathrm{~h}$ at $4{ }^{\circ} \mathrm{C}$ with affinity-purified rabbit antibodies against rat collagen I (Timpl, 1982), which react with both the $\alpha 1$ (I) and $\alpha 2$ (I) chains. Immune complexes were precipitated by using Tachisorb (Hoechst AG, Frankfurt, Germany), and dissociated by boiling in SDS-containing sample buffer (Laemmli, 1970) before 5\%-(w/v)polyacrylamide-gel electrophoresis.

Procollagen III was assayed in fractions of the medium by a radioimmunoinhibition assay specific for the aminopropeptide of bovine procollagen III (Rohde et al., 1979) supplied by Dr. D. Brocks (Hoechst AG, Frankfurt, Germany), which showed sufficient cross-reactivity with mouse antigens.

\section{RESULTS}

Labelling of fibroblast-like mouse cell lines with $\left[{ }^{3} \mathrm{H}\right]$ proline demonstrated a similar total incorporation into protein-bound form (proline plus hydroxyproline) for all three genotypes examined, with some variations between uncloned and cloned cells (Table 1). The amounts of newly synthesized collagens were calculated from these data by assuming that non-dialysable $\left[{ }^{3} \mathrm{H}\right]$ hydroxyproline is unique to collagen chains. Quantification of total collagen synthesized by the cloned and uncloned cell lines from each genotype indicated a marked decrease in $\left[{ }^{3} \mathrm{H}\right]$ hydroxyproline radioactivity per cell for the homozygous cell lines when compared with wild-type or heterozygous cells (Table 1). This was evident in both the medium and cell-layer fractions, although the amount of newly labelled collagen associated with the cell layer was usually low $(<30 \%)$. Synthesis of non-collagenous proteins, as estimated from the difference between proline and hydroxyproline radioactivity (Krieg et al., 1978) did not reveal the same large differences between genotypes that were observed

Table 1. Collagen synthesis by uncloned (uc) and cloned (c) wild-type embryo fibroblast-like cell lines $(+/+)$ and heterozygous $(\mathbf{M} /+)$ and homozygous (M/M) cell lines from the Mov-13 mutation

Synthesis is expressed as c.p.m. of hydroxyproline (Hyp) produced per 1000 cells compared with c.p.m. of proline (Pro), calculated from non-dialysable radioactivity from the medium and cell layer. Values represent averages for at least two duplicate samples from three separate labelled dishes. Collagen synthesis as a proportion of total protein synthesis was calculated as described by Krieg et al. (1978) on the assumption that collagen contains as much hydroxyproline as proline and that non-collagenous proteins contain five times less proline and hydroxyproline than collagen. The amount of collagen secreted from the cell layer is calculated from c.p.m. of collagen in the medium fraction as a percentage of total collagen c.p.m. within the cell culture.

\begin{tabular}{|c|c|c|c|c|c|c|c|}
\hline \multirow{3}{*}{$\begin{array}{l}\text { Cell } \\
\text { type }\end{array}$} & \multicolumn{3}{|c|}{ Medium } & \multicolumn{3}{|c|}{ Cell layer } & \multirow{3}{*}{$\begin{array}{c}\text { Collagen } \\
\text { secreted }(\%)\end{array}$} \\
\hline & \multicolumn{2}{|c|}{$\begin{array}{l}\text { Radioactivity } \\
\text { (c.p.m. } / 10^{3} \text { cells) }\end{array}$} & \multirow{2}{*}{$\begin{array}{c}\text { Collagen } \\
(\%)\end{array}$} & \multicolumn{2}{|c|}{$\begin{array}{c}\text { Radioactivity } \\
\text { (c.p.m. } / 10^{3} \text { cells) }\end{array}$} & \multirow{2}{*}{$\begin{array}{c}\text { Collagen } \\
(\%)\end{array}$} & \\
\hline & Pro & Нyp & & Pro & Hyp & & \\
\hline $\mathrm{uc},+/+$ & 840 & 141 & 7.5 & 2480 & 31 & 0.5 & 85 \\
\hline c, $+/+$ & 564 & 196 & 17.6 & 612 & 60 & 4.2 & 83 \\
\hline uc, $\mathbf{M} /+$ & 768 & 130 & 7.5 & 1898 & 28 & 0.6 & 85 \\
\hline c, $\mathbf{M} /+$ & 515 & 94 & 8.2 & 430 & 5 & 0.5 & 96 \\
\hline uc, $\mathbf{M} / \mathbf{M}$ & 570 & 28 & 2.0 & 2202 & 12 & 0.2 & 71 \\
\hline $\mathrm{c}, \mathbf{M} / \mathbf{M}$ & 793 & 36 & 1.9 & 306 & 1 & 0.2 & 97 \\
\hline
\end{tabular}


(a)

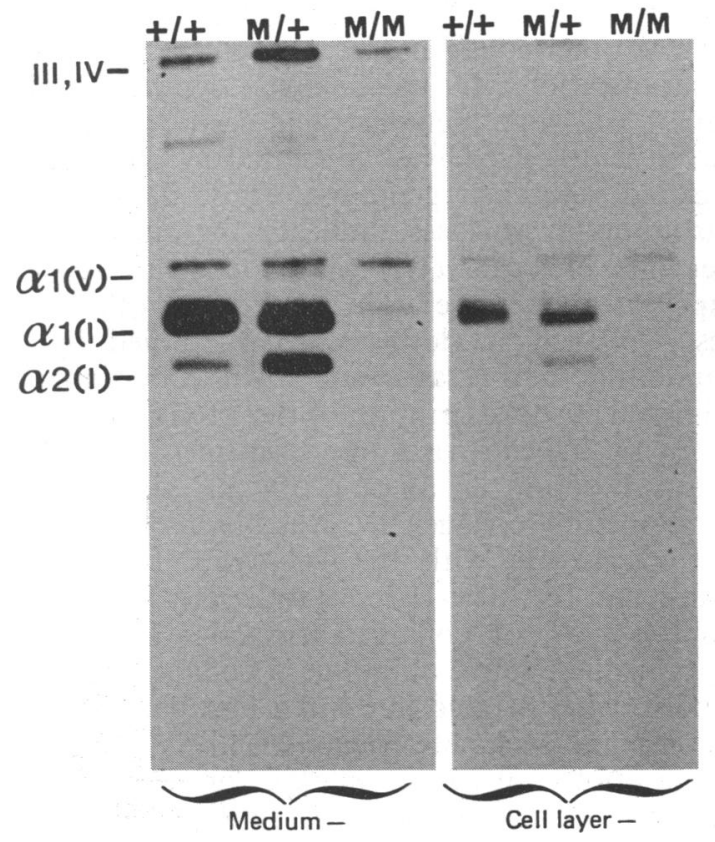

(b)
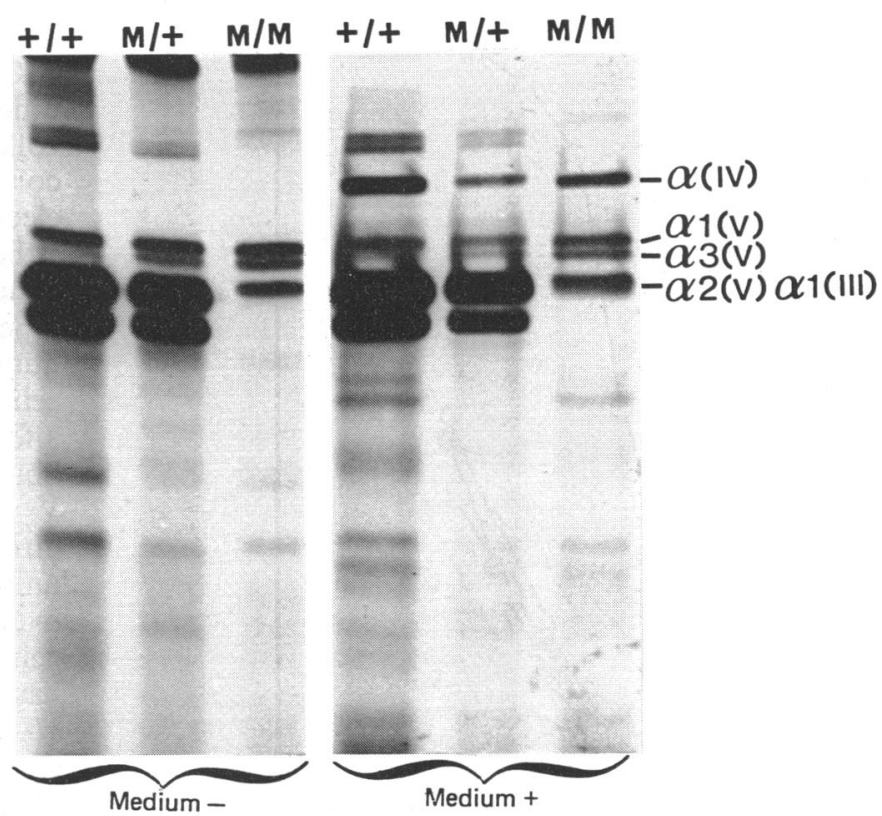

Fig. 1. Gel electrophoresis of $\left[{ }^{3} \mathbf{H}\right]$ proline-labelled, pepsin-digested samples from cell layer and/or medium fractions of uncloned wild-type $(+/+)$, heterozygous $(\mathbf{M} /+)$ and homozygous $(\mathbf{M} / \mathbf{M})$ cell lines in $(a)$ and cloned cell lines in $(b)$

Samples were run on SDS $/ 5 \%(w / v)$ polyacrylamide gels without reduction $(-)$ or after reduction $(+)$ with 2-mercaptoethanol, followed by autoradiography. The positions of unreduced collagen III and IV, and $\alpha 1(\mathrm{I}), \alpha 2(\mathrm{I}), \alpha 1(\mathrm{~V}), \alpha 2(\mathrm{~V})$ and $\alpha 3(\mathrm{~V}) \mathrm{chains}$ are shown.

for collagen production (Table 1). Labelled procollagen $\alpha$-chains were analysed by gel electrophoresis after immunoprecipitation with antibodies against collagen $I$. Whereas $\alpha 1(\mathrm{I})$ and $\alpha 2(\mathrm{I})$ chains of procollagen and partially processed procollagens could be distinguished in wild-type and heterozygous cell lines on the basis of their migration position relative to pepsin-digested samples, neither $\alpha 1$ (I) nor $\alpha 2$ (I) procollagen chains were detected in medium or cell-layer fractions of homozygous cell lines (results not shown). Since the electrophoretic pattern of total $\left[{ }^{3} \mathrm{H}\right]$ proline-labelled proteins was rather complex, further analysis of the collagen types synthesized exploited the resistance of triple-helical collagen molecules to pepsin digestion. Analysis of pepsin-digested medium and cell extracts by gel electrophoresis indicated the presence of both collagen $\alpha 1$ (I) and $\alpha 2$ (I) chains in wild-type and heterozygous, but not homozygous, cell lines (Fig. 1). These data indicate that stable $\alpha 2$ (I) chain trimers are not produced by the homozygous cells. Both the $\alpha 1$ (I) and $\alpha 2(I)$ chains of collagen I were present at higher levels in the cloned wild-type cell line when compared with the heterozygous cell line (Fig. 1b). The level of $\alpha 1(\mathrm{I})$ collagen chains in the different cell lines correlated well with the presence of two $(+/+)$, one $(\mathrm{M} /+)$ or no $(\mathrm{M} / \mathrm{M})$ active copies of the $\alpha 1(\mathrm{I})$ gene in the three genotypes.

Other collagens produced by all cell lines were identified as $\alpha$-chains of collagens III, IV and $V$ by comparison with purified collagen standards on gel electrophoresis under reducing and non-reducing conditions. The fibril-forming collagens III and $\mathrm{V}$ are potential candidates that could compensate for the absence of collagen I. Collagen $\alpha$ (IV) chains appeared in similar amounts in all genotypes within the cloned or uncloned groups of cell lines. Collagen $\alpha 2(\mathrm{~V})$ chains co-migrate with $\alpha 1$ (I) collagen chains, and could not be distinguished. Because of interchain disulphide bonding, unreduced collagens III and IV migrate as $\gamma$-components at the top of the resolving gel (Fig. 1). Reduced $\alpha$ (III) chains co-migrate with $\alpha 1(\mathrm{I})$ and $\alpha 2(\mathrm{~V})$ collagen chains, and cannot be quantified after electrophoresis. The amount of collagen III produced by the cell lines was therefore quantified by a specific procollagen III radioimmunoassay. The inhibition curves obtained with samples of the medium after a $24 \mathrm{~h}$ incubation period in serum-free medium are virtually superimposable (Fig. 2), indicating little variation in the levels of procollagen III synthesized by the different genotypes.

Some variation was observed in the overall pattern of collagen chains synthesized by the different cell lines. The lower-than-normal amounts of $\alpha 2(\mathrm{I})$ collagen chain produced by the uncloned wild-type cell line (Fig. 1) suggests a predominance of $\alpha 1$ (I) trimer assembly by this cell line, compared with an apparently normal $[\alpha 1(\mathrm{I})]_{2} \alpha 2$ (I) configuration of collagen I molecules in the other cell lines. An additional $\alpha 3(\mathrm{~V})$ chain of collagen $\mathrm{V}$ was prominent in the cloned homozygous cell lline, which was less distinct in the heterozygous line, and only weakly visible in the wild-type cell line (Fig. 1b). The presence of $\alpha 3(\mathrm{~V})$ chains appeared not to be a specific response to the Mov-13 mutation, since a similar pattern was not seen in the uncloned cell lines (Fig. 1a). Variation between cell lines was also seen in the amount of a reducible collagen species which we have tentatively identified as collagen IV by its electrophoretic properties (Fig. 1b). 


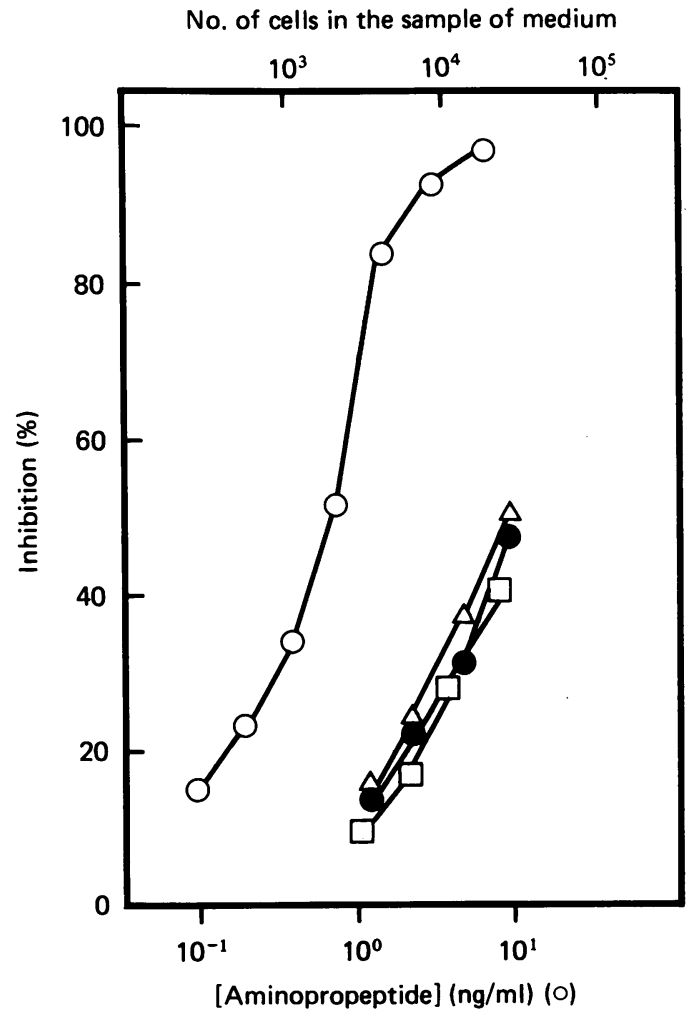

Fig. 2. inhibition of binding of antiserum against the aminopropeptide of procollagen III to the labelled peptide in radioimmunoinhibition assay by culture medium from the cell lines

Inhibitors of the reaction were the bovine aminopropeptide (O) and culture medium from wild-type (O), heterozygous $(\triangle)$ and homozygous $(\square)$ cell lines. Results are the averages of three separate determinations from the cloned and uncloned cell lines and are expressed as a decrease in binding of the antibody compared with non-inhibited control.

\section{DISCUSSION}

In the present study we have analysed collagen synthesis by transformed fibroblast-like cell lines derived from Mov-13 mouse embryos in which the expression of the collagen $\alpha 1(\mathrm{I})$ gene is completely blocked. Collagen $\alpha 1(\mathrm{I})$ and $\alpha 2(\mathrm{I})$ chains could not be detected after pepsin digestion or as procollagen chains in undigested culture medium or cell layers from homozygous cell lines, a finding analogous to that for embryonic organ cultures (Kratochwil et al., 1986). Since collagen $\alpha 2(I)$ mRNA is produced in normal amounts in homozygous cells (Schnieke et al., 1983) and is presumably translated, the absence of detectable procollagen $\alpha 2$ (I) chains would be consistent with rapid degradation. It has been shown that $\alpha 2(I)$ chains are able to form triple helices in solution, but that these are not stable at $37^{\circ} \mathrm{C}$, in contrast with $\alpha 1(\mathrm{I})$ trimers, which are as stable as normal $[\alpha 1(\mathrm{I})]_{2} \alpha 2(\mathrm{I})$ molecules (Tkocz \& Kühn, 1969). Collagen $\alpha$-chains, which cannot be incorporated into stable triple-helical molecules, are rapidly degraded intracellularly (Bienkowski, 1984; Prockop \& Kivirikko, 1984). For instance, defective $\alpha 2$ (I)-chain production by a patient with non-lethal osteogenesis imperfecta results in rapid degradation of these chains (Nicholls et al., 1979; Chu et al., 1984). Our data also demonstrate that $\alpha 2$ (I) chains do not assemble into a triple helix with procollagen $\alpha$ (III) chains or other collagen $\alpha$-chains.

Quantification of total collagen synthesized by the different cell lines demonstrated that the amount of collagen synthesized was not equal in these cells, but correlated with their genotype. These data, as well as electrophoretic analyses, indicate that inactivation of either one or both $\alpha 1$ (I) genes does not result in a compensatory increase in the synthesis or other collagen types. Collagen III levels were quantified by radioimmunoinhibition assays and shown to be similar in all cell lines. Thus transcription of the $\alpha 1$ (III) gene was not affected by the retroviral insertion into the $\alpha 1$ (I) gene. Some variation in the amount of expression of collagen $\mathrm{V}$, and possibly collagen IV, was observed that did not directly correlate with the genotype. It is therefore unlikely that the Mov-13 locus is directly influencing the overall pattern of collagen synthesis. Clonal heterogeneity in the relative amounts of collagens synthesized has been demonstrated in human fibroblasts (Bordin et al., 1984), and such heterogeneity is likely to account for the variations observed in the present study. An additional collagen species was detected as a synthetic product in some Mov-13 homozygous embryonic tissues, which migrated close to the $\alpha 1(\mathrm{I})$ collagen chain (Kratochwil et al., 1986). This protein was not produced by the homozygous cell lines used in the present study, suggesting that it is not a product of fibroblast-like cells, or that synthesis is inhibited by simian-virus-40 transformation.

The present study shows that the Mov-13 mutation is maintained in transformed fibroblast-like cell lines derived from mouse embryos, generating, for the first time, permanent cell lines that are specifically and completely blocked in their expression of the collagen $\alpha 1(I)$ gene. These cell lines have been used for transfection of mouse or human $\alpha 1$ (I) genes, resulting in normal levels of collagen I expression (Schnieke et al., 1987). It is not feasible to use these lines for transfection and analysis of expression of collagen $\alpha 1$ (I) genes into which specific mutations have been introduced.

We are grateful to Mrs. Vera van Delden and Mrs. Danica Veranic for assistance with amino acid analysis, and to Dr. Monique Aumailley for discussions. This work was supported by a grant from the Deutsche Forschungsgemeinschaft. M.D. was in receipt of fellowships from the European Molecular Biology Organization and the Alexander von Humboldt Foundation.

\section{REFERENCES}

Aumailley, M., Krieg, T., Razaka, G., Müller, P. K. \& Bricaud, H. (1982) Biochem. J. 206, 505-510

Bienkowski, R. S. (1984) Collagen Relat. Res. 4, 399-411

Bonner, W. M. \& Laskey, R. A. (1974) Eur. J. Biochem. 46, 83-88

Bordin, S., Page, R. C. \& Narayanan, A. S. (1984) Science 223, 171-173

Bornstein, P. \& Sage, H. (1980) Annu. Rev. Biochem. 49, 957-1004

Breindl, M., Harbers, K. \& Jaenisch, R. (1984) Cell 38, 9-16

Chu, M.-L., Rowe, D., Nicholls, A. C., Pope, F. M. \& Prockop, D. J. (1984) Collagen Relat. Res. 4, 389-394

Hartung, S., Jaenisch, R. \& Breindl, M. (1986) Nature (London) 320, 365-367 
Jaenisch, R., Harbers, K., Schnieke, A., Löhler, J., Chumakov, I., Jähner, D., Grotkopp, D. \& Hoffmann, E. (1983) Cell 32, 209-216

Kratochwil, K., Dziadek, M., Löhler, J., Harbers, K. \& Jaenisch, R. (1986) Dev. Biol. 117, 596-606

Krieg, T., Hörlein, D., Wiestner, M. \& Müller, P. K. (1978) Arch. Dermatol. Res. 263, 171-180

Laemmli, U. K. (1970) Nature (London) 227, 680-685

Löhler, J., Timpl, R. \& Jaenisch, R. (1984) Cell 38, 597-607

Miller, E. J. \& Rhodes, R. K. (1982) Methods Enzymol. 82, 33-64

Nicholls, A. C., Pope, F. M. \& Schloon, H. (1979) Lancet i, 1193

Received 20 January 1987/4 March 1987; accepted 11 March 1987
Prockop, D. J. \& Kivirikko, K. I. (1984) N. Engl. J. Med. 311, 376-386

Rohde, H., Vargas, L., Hahne, E., Kalbfleisch, H., Bruguera, M. \& Timpl, R. (1979) Eur. J. Clin. Invest. 9, 451-459

Schnieke, A., Harbers, K. \& Janiesch, R. (1983) Nature (London) 304, 315-320

Schnieke, A., Dziadek, M., Bateman, J., Mascara, T., Harbers, K., Gelinas, R. \& Jaenisch, R. (1987) Proc. Natl. Acad. Sci. U.S.A. 84, 764-768

Timpl, R. (1982) Methods Enzymol. 82A, 472-498

Tkocz, C. \& Kühn, K. (1969) Eur. J. Biochem. 7, 454462

Uitto, J. (1979) Arch. Biochem. Biophys. 192, 371-379 